TITLE:

\title{
Measurements of atomic carbon density in processing plasmas by vacuum ultraviolet laser absorption spectroscopy
}

\author{
$\operatorname{AUTHOR}(\mathrm{S}):$ \\ Tanaka, N; Tachibana, K
}

\section{CITATION:}

Tanaka, N ... [et al]. Measurements of atomic carbon density in processing plasmas by vacuum ultraviolet laser absorption spectroscopy. JOURNAL OF APPLIED PHYSICS 2002, 92(10): 5684-5690

ISSUE DATE:

2002-11-15

URL:

http://hdl.handle.net/2433/50090

\section{RIGHT:}

Copyright 2002 American Institute of Physics. This article may be downloaded for personal use only. Any other use requires prior permission of the author and the American Institute of Physics. 


\title{
Measurements of atomic carbon density in processing plasmas by vacuum ultraviolet laser absorption spectroscopy
}

\author{
Norifusa Tanaka ${ }^{a)}$ and Kunihide Tachibana ${ }^{\text {b) }}$ \\ Department of Electronic Science and Engineering, Kyoto University, Yoshida-Honmachi, Sakyo-ku, \\ Kyoto 606-8501, Japan
}

(Received 28 May 2002; accepted 21 August 2002)

\begin{abstract}
Measurements of the absolute $\mathrm{C}$ atom density in an inductively coupled plasma (ICP) source were carried out by using vacuum ultraviolet (VUV) laser absorption spectroscopy with the resonance lines of $\mathrm{C}$ atoms at wavelengths around 94.5 and $165.7 \mathrm{~nm}$. A tunable VUV laser covering these wavelength ranges was generated by a two-photon resonance/four-wave mixing technique in Xe gas. No absorption at around $94.5 \mathrm{~nm}$ could be observed, but from the absorption spectra around $165.7 \mathrm{~nm}$ we successfully derived the absolute density of $\mathrm{C}$ atoms in the ICP source. The obtained values varied from $1 \times 10^{10}$ to $1 \times 10^{11} \mathrm{~cm}^{-3}$, depending on the source gas and operating conditions of the plasma source. The relatively small density values compared to other atomic species are attributed to the large loss rates, which mostly occur on the surface. (C) 2002 American Institute of Physics. [DOI: 10.1063/1.1513877]
\end{abstract}

\section{INTRODUCTION}

There has been much discussion on the roles of $\mathrm{C}$ atoms produced in plasmas of fluorocarbon and hydrocarbon gases for various kinds of plasma material processing. For example, in plasma etching processes for the production of ultralarge-scale integration (ULSI) devices, fluorocarbon plasmas have been used for selective etching of $\mathrm{SiO}_{2}$ on $\mathrm{Si}$, $\mathrm{Si}_{3} \mathrm{~N}_{4}$, and under photoresist. However, the poor reproducibility of the etch rate and inadequate selectivity have sometimes caused severe problems. A sophisticated balance between etching and deposition can achieve the selectivity where not only $\mathrm{CF}_{x}(x=1-3)$ radicals and $\mathrm{F}$ atoms but also $\mathrm{C}$ atoms may play important roles in the mechanism. ${ }^{1}$ In plasma-enhanced chemical vapor deposition (PECVD) processes for diamond and diamond-like carbon films, controversial reports have stated that $\mathrm{C}$ atoms in the gas phase have a positive or negative correlation with the characteristics of high mechanical hardness, thermal conductivity, and chemical stability. ${ }^{2-4}$

Recently, in using low-pressure and high-density plasma sources, ${ }^{5}$ such as inductively coupled plasma (ICP), electron cyclotron resonance (ECR) plasma, and helicon-wave excited plasma (HWP), the increased dissociation of source gases has made the gas chemistry more complex. Therefore quantitative in situ diagnostics of radical densities as well as plasma parameters are necessary to clarify the kinetics of these plasmas in the gas phase and on the surface in order to control those processes more precisely. Although much work has been done on the quantitative measurements of molecular radicals such as $\mathrm{CF}_{x}(x=1-3),{ }^{6}$ quantitative and reliable measurements of $\mathrm{C}$ and $\mathrm{F}$ atoms have not yet been performed. Some methods have been developed for the mea-

\footnotetext{
${ }^{a)}$ Present address: Mobile Entertainment Co., Pioneer Corp., Yamada, Kawagoe, Saitama 350-8555, Japan.

${ }^{b)}$ Author to whom correspondence should be addressed; electronic mail: tatibana@kuee.kyoto-u.ac.jp
}

surement of these atomic species, such as two-photon absorption laser-induced fluorescence ${ }^{7,8}$ and line absorption spectroscopy in the vacuum-ultraviolet wavelength region with conventional (incoherent) light sources. ${ }^{9,10}$ However, the former method requires a laser source with a sufficient power level, and absolute density calibration is not an easy task. ${ }^{11}$ In the latter method, other errors in the derivation of absolute density have been caused by the influence of background absorption by source gas molecules and species produced in plasma as well as by inaccurate estimation of the line shape of the light source. Therefore we have been developing an absolute measurement system for these species by using vacuum ultraviolet laser absorption spectroscopy (VUVLAS). ${ }^{12-14}$ In this method, the VUV laser is generated by a two-photon resonance four-wave mixing technique, and its tunability permits accurate determination of absolute values from the integrated absorption line shapes. This technique has been successfully applied to the measurement of $\mathrm{F}$ atoms in the plasmas of various fluorocarbon source gases. ${ }^{12,13}$ In this study, we report on measurements of C atom density by the same technique in the wavelength ranges around 94.5 and $165.7 \mathrm{~nm}$. These measurements were performed in an ICP source with various carbon-containing source gases.

\section{EXPERIMENTAL PROCEDURE}

Figure 1 shows a schematic diagram of the experimental setup for the measurement of $\mathrm{C}$ atom density using VUVLAS. In order to generate a tunable VUV laser of wavelengths around 94.5 and $165.7 \mathrm{~nm}$, we used a two-photon resonance/four-wave mixing technique ${ }^{15,16}$ in Xe gas $\left(\nu_{\mathrm{VUV}}\right.$ $\left.=2 \nu_{1} \pm \nu_{2}\right)$, as in the case of our previous $\mathrm{F}$ atom measurement. ${ }^{12,13}$ Two dye lasers pumped simultaneously by a $\mathrm{Xe}-\mathrm{Cl}$ excimer laser provided the frequencies (wavelengths) of $\nu_{1}\left(=c / \lambda_{1}\right)$ and $\nu_{2}\left(=c / \lambda_{2}\right)$, where $c$ is the light velocity. The energy of two photons $2 h \nu_{1}$, where $h$ is the 


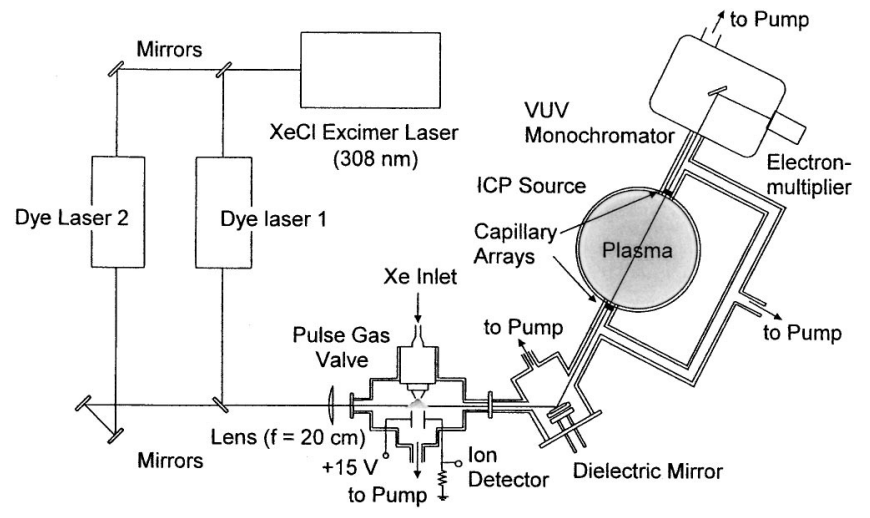

FIG. 1. Experimental setup for VUVLAS measurement combined with an ICP plasma reactor.

Planck constant, was set in resonance with the energy level of Xe ( $2 p_{1}$ : Paschen notation) from the ground state at $\lambda_{1}$ $=249.63 \mathrm{~nm}$ (Fig. 2), while $\lambda_{2}$ was varied between 380 and $400 \mathrm{~nm}$ or between 504 and $506 \mathrm{~nm}$ to obtain a tunable VUV laser in the range from 94.0 to $95.0 \mathrm{~nm}$ (in sum-frequency generation scheme) or from 165.6 to $165.8 \mathrm{~nm}$ (in difference-frequency generation scheme). The two-photon resonance was adjusted by optimizing the current from ( 2 +1 ) photoionization of $\mathrm{Xe}$ atoms. Two dye laser beams were aligned collinearly and focused by a lens of $f=20 \mathrm{~cm}$ into the VUV generation chamber, where these frequencies were mixed to generate $\nu_{\mathrm{VUV}}$. In the case of sum-frequency generation, Xe gas was injected into the chamber synchronously with the two lasers, since differential pumping was necessary due to the lack of window materials at this wavelength. On the other hand, in the case of differencefrequency generation, Xe gas was filled in the chamber at a fixed pressure of 20 Torr with a $\mathrm{MgF}_{2}$ sealing window at the exit side. The generated VUV radiation was reflected by the surface of an uncoated concave quartz plate of $1 \mathrm{~m}$ curvature, which was placed in another small chamber at an incident angle of $65^{\circ}$. The quartz plate acts partially in collimating the VUV beam and also in separating it from the

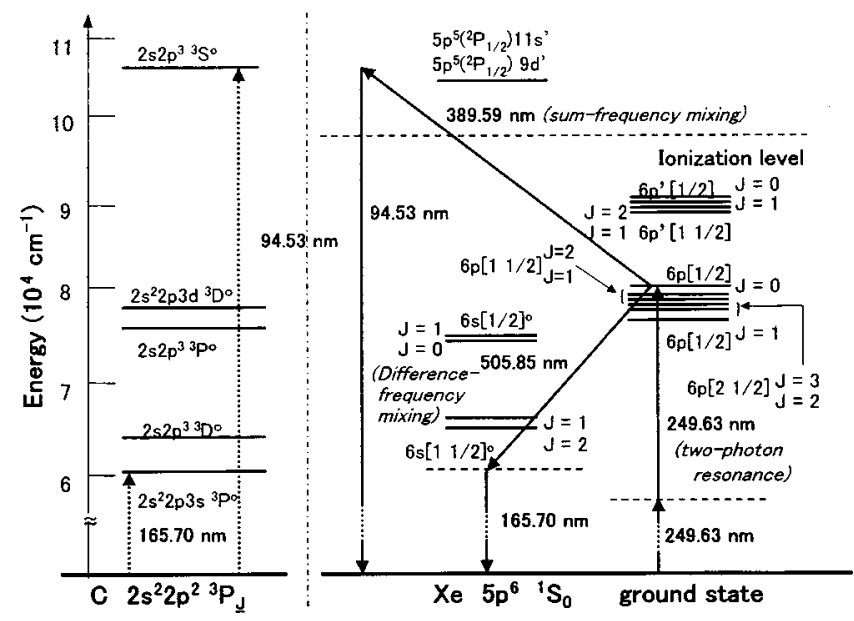

FIG. 2. Partial energy level diagrams of $\mathrm{Xe}$ and $\mathrm{C}$ atoms as explanations of VUV generation and VUVLAS measurement. fundamental wavelengths, since the reflectivity in the VUV range (expected to be more than 20\%) is larger than that for the UV-to-visible range. ${ }^{17}$ The VUV laser power was high enough to obtain a reasonable signal-to-noise ratio but low enough to avoid the pumping effect of the lower level of the transition, as checked by changing the power level by a factor of $5 .^{14}$

The ICP chamber was $32 \mathrm{~cm}$ in inner diameter and 15 $\mathrm{cm}$ in height. A substrate holder of $22 \mathrm{~cm}$ in diameter was located $8.5 \mathrm{~cm}$ below the quartz plate, and $\mathrm{rf}(13.56 \mathrm{MHz})$ power up to $600 \mathrm{~W}$ was supplied by a flat spiral four-turn antenna coil into the plasma reactor through a quartz plate of $19 \mathrm{~cm}$ in diameter and $1.5 \mathrm{~cm}$ in thickness. Source gases $\left(\mathrm{CH}_{4}, \mathrm{CF}_{4}, \mathrm{CHF}_{3}, \mathrm{C}_{4} \mathrm{~F}_{8}, \mathrm{C}_{5} \mathrm{~F}_{8}\right.$, and $\left.\mathrm{CO}\right)$ and dilution gas $\mathrm{Ar}$ were introduced into the chamber from a side port at a pressure range from 1.3 to $13.3 \mathrm{~Pa}$. The laser beam was fed into the chamber through the capillary array windows mounted on both sides of the chamber at $2 \mathrm{~cm}$ above the substrate holder. The VUV laser path was differentially pumped, so the windows also functioned to sustain the pressure difference. In this configuration, the absorption length was close to the inner diameter of the chamber and was taken to be 32 $\mathrm{cm}$. The VUV probe beam coming out of the chamber was further filtered by a VUV monochromator of $f=20 \mathrm{~cm}$ and detected by a $\mathrm{Cu}-\mathrm{BeO}$ electron multiplier for the $94.5 \mathrm{~nm}$ range and by a solar blind photomultiplier for the $165.7 \mathrm{~nm}$ range.

The partial energy level diagram of $\mathrm{C}$ is shown in Fig. 2 together with that of the Xe atom to illustrate the relatioship between the generated VUV laser and the absorption measurement. The measurement was performed on the $2 s^{2} 2 p^{2}{ }^{3} P_{J}-2 s 2 p^{3}{ }^{3} S_{1}{ }^{o}(J=0,1,2)$ transition at around $94.5 \mathrm{~nm}$ and the $2 s^{2} 2 p^{2}{ }^{3} P_{J}-2 s^{2} 2 p 3 s^{3} P_{J}^{o}(J=0,1,2)$ transition at around $165.7 \mathrm{~nm}$. Provided that the corresponding transition probability $A_{u l}$ is known, the absolute density populated on each lower level $N_{l}$ can be derived from the integrated area of the profile of absorption coefficient per unit length $k_{u l}(\nu)$ as

$$
N_{l}=\frac{8 \pi g_{l}}{\lambda_{0}^{2} g_{u} A_{u l}} \int k_{u l}(\nu) d \nu,
$$

where $\lambda_{0}$ is the wavelength and $g_{l}$ and $g_{u}$ are the statistical weights of the lower and upper levels of the transition. It is noted here that an obtained value of $N_{l}$ gives inherently the averaged value over the line-of-sight (the absorption length was assumed to be $32 \mathrm{~cm}$ as stated above).

The effect of background absorption due to source gas and product species can be eliminated by scanning the laser frequency as explained previously. ${ }^{12}$ The estimated error in the determination of $N_{l}$ mainly comes from the data reproducibility $(10 \%-20 \%)$, uncertainty in the evaluation of the $k_{u l}(\nu)$ profile for the integration $(\sim 20 \%)$, and the uncertainty in the reported value of the transition probability $(10 \%)$. Therefore the total error may amount up to $30 \%$.

\section{EXPERIMENTAL RESULTS}

First, we attempted a VUVLAS measurement at the $2 s^{2} 2 p^{2}{ }^{3} P_{J}-2 s 2 p^{3}{ }^{3} S_{1}^{o}(J=0,1,2)$ transition around 94.5 


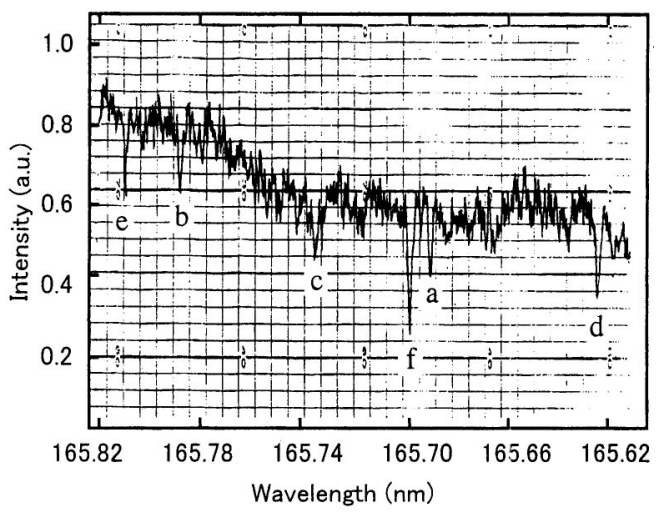

(a)

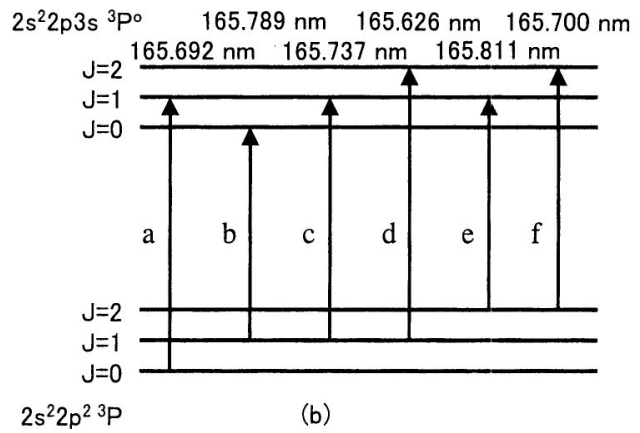

FIG. 3. (a) Measured absorption spectra and (b) corresponding transitions of resonance lines within the $2 s^{2} 2 p^{2}{ }^{3} P_{J}-2 s^{2} 2 p 3 s^{3} P_{J}^{o}(J=0,1,2)$ group.

$\mathrm{nm}$, since the literature values of the transition probability are extremely large: $3.79 \times 10^{8}, 1.14 \times 10^{9}$, and 1.89 $\times 10^{9} \mathrm{~s}^{-1}$ for the $94.52,94.53$, and $94.56 \mathrm{~nm}$ lines, respectively, ${ }^{18}$ and the wavelengths are close to those of $\mathrm{F}$ atoms which we have measured previously. ${ }^{12,13}$ However, no absorption signal could be observed within the scanned wavelength range from 94.0 to $95.0 \mathrm{~nm}$, although various source gases including $\mathrm{CO}$ and fluorocarbon gases were tested. Then, we tried to observe the emission at around 94.5 $\mathrm{nm}$ in the ICP source operated with pure source gases and also in a dc discharge in Ar with a carbon hollow cathode operated at a pressure of $4.0 \mathrm{~Pa}$ and a current of $20 \mathrm{~mA}$. Unfortunately, we were not able to observe any emission spectra at around $94.5 \mathrm{~nm}$ in either case, although in the latter case closely lying $\mathrm{Ar}^{+}$lines might have obscured the emission.

Then, we proceeded to the VUVLAS measurement at the $165 \mathrm{~nm}\left(2 s^{2} 2 p^{2}{ }^{3} P_{J}-2 s^{2} 2 p 3 s^{3} P_{J}^{o}\right)$ transition group. The signals observed in the spectral range between 165.62 and

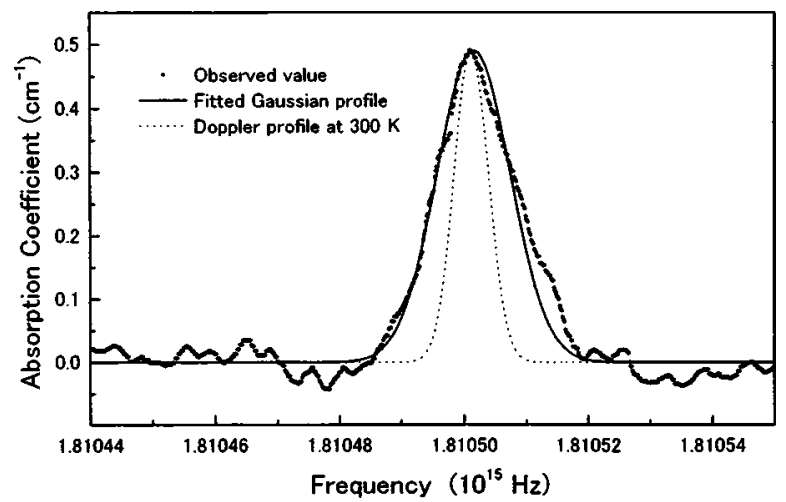

FIG. 4. Typical absorption line profile of $165.700 \mathrm{~nm}\left(2 s^{2} 2 p^{2}{ }^{3} P_{2}\right.$ $-2 s^{2} 2 p 3 s^{3} P_{2}{ }^{o}$ ) line.

$165.82 \mathrm{~nm}$ in CO/Ar plasma are shown in Fig. 3(a). The flow rates of $\mathrm{CO}$ and $\mathrm{Ar}$ gases were 10 and $20 \mathrm{sccm}$ (standard $\mathrm{cm}^{3} / \mathrm{min}$ ), the total pressure was $4.0 \mathrm{~Pa}$, and the supplied $\mathrm{rf}$ power was $400 \mathrm{~W}$. The absorption feature composed of the six isolated lines in Fig. 3(b) is clearly seen in this result owing to the fairly high resolution of our VUVLAS technique. The $\mathrm{C}$ atom densities derived from these six absorption lines using Eq. (1) are listed in Table I. Assuming the Boltzmann distribution within the ground state levels at a temperature of $300 \mathrm{~K}$, the ratio of $\mathrm{C}$ atom densities on the ${ }^{3} P_{2},{ }^{3} P_{1}$, and ${ }^{3} P_{0}$ levels divided by the respective statistical weights should be 0.809:0.926:1. From Table I, it is evident that $\mathrm{C}$ atom densities obtained from these absorption lines nearly correspond to this ratio except for the value from the $165.700 \mathrm{~nm}$ line. If we suppose that overestimation of the transition probability is the cause of this disagreement, the transition probability of $165.700 \mathrm{~nm}$ predicted from this result would be smaller than the reported value ${ }^{18}$ by about $20 \%$. In order to ascertain the transition probability ratios, we tried to measure the intensity ratios of emission lines within the $165 \mathrm{~nm}$ group from the same carbon hollow cathode discharge used above. In this case, emission peaks around $165.7 \mathrm{~nm}$ were observed, but the six lines could not be fully resolved due to the limited resolution of the VUV monochromator used.

Figure 4 shows an example of the absorption coefficient $k_{u l}(\nu)$ as a function of frequency $\nu$ for the $165.700 \mathrm{~nm}$ $\left(2 s^{2} 2 p^{23} P_{2}-2 s^{2} 2 p 3 s^{3} P_{2}{ }^{o}\right)$ line. Its full width at half maximum (FWHM) was estimated to be $1.43 \times 10^{-3} \mathrm{~nm}$, which was about two times larger than that of the Doppler profile at $300 \mathrm{~K}$, i.e., $0.685 \times 10^{-3} \mathrm{~nm}$. The difference may

TABLE I. Population densities on ground state levels $(l \equiv J=0,1,2)$ measured with various absorption lines.

\begin{tabular}{lcccccc}
\hline \hline $\begin{array}{l}\text { Lower energy } \\
\text { level }\end{array}$ & $\begin{array}{c}\text { Statistical } \\
\text { weight } g_{l}\end{array}$ & Wavelength $(\mathrm{nm})$ & $\begin{array}{c}\text { Transition } \\
\text { probability } \\
\left(10^{8} \mathrm{~s}^{-1}\right)\end{array}$ & $\begin{array}{c}\text { Measured } \\
\text { density } \\
N_{l}\left(\mathrm{~cm}^{-3}\right)\end{array}$ & $\begin{array}{c}\text { Normalized } \\
\text { density } \\
N_{l} / g_{l} N_{0}\end{array}$ & $\begin{array}{c}\text { Normalized } \\
\text { Boltzmann } \\
\text { factor }\end{array}$ \\
\hline $2 s^{2} 2 p^{2}{ }^{3} P_{0}$ & 1 & 165.692 & 1.13 & $1.65 \times 10^{10}$ & 1 & 1 \\
$2 s^{2} 2 p^{2} P_{1}$ & 3 & 165.789 & 3.43 & $3.98 \times 10^{10}$ & 0.804 & 0.926 \\
$2 s^{2} 2 p^{2}{ }^{3} P_{1}$ & 3 & 165.737 & 0.864 & $4.19 \times 10^{10}$ & 0.846 & 0.926 \\
$2 s^{2} 2 p^{23} P_{1}$ & 3 & 165.626 & 0.858 & $3.97 \times 10^{10}$ & 0.802 & 0.926 \\
$2 s^{2} 2 p^{2} P_{2}$ & 5 & 165.811 & 1.44 & $6.56 \times 10^{10}$ & 0.795 & 0.809 \\
$2 s^{2} 2 p^{23} P_{2}$ & 5 & 165.700 & 2.52 & $4.17 \times 10^{10}$ & 0.505 & 0.809 \\
\hline \hline
\end{tabular}




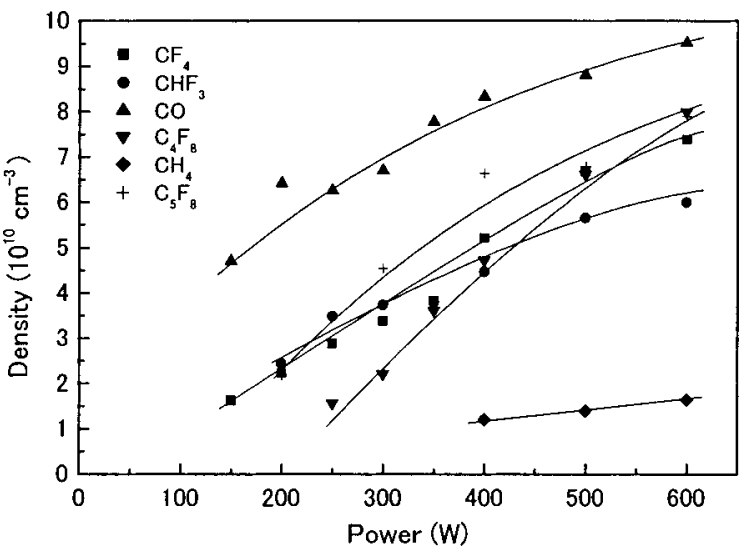

FIG. 5. rf power dependence of $\mathrm{C}$ atom densities measured in plasmas of fluorocarbon, methane, and $\mathrm{CO}$ gases at a total pressure of $2.7 \mathrm{~Pa}$ with flow rates of source gas and Ar of 10 and $20 \mathrm{sccm}$, respectively.

be attributed mostly to the finite spectral width of our VUV laser, but another contributing factor may be the nonthermalized velocity distribution of $\mathrm{C}$ atoms produced by electron collisional dissociation. Nevertheless, the absolute density can be derived accurately from the integrated area of $k_{u l}(\nu)$ over the absorption coefficient profile given in Eq. (1) without any influence of the instrumental width. We used this $165.700 \mathrm{~nm}$ line representatively for the rest of the measurements because its absorption was the largest among the six lines. The total density of three levels, $N=\Sigma_{l} N_{l}$, in the ground state was estimated by using the experimental ratio given in Table I.

The absolute $\mathrm{C}$ atom density in the ground state measured in various source gases as a function of $\mathrm{rf}$ power is shown in Fig. 5. Each source gas with a flow rate of $10 \mathrm{sccm}$ was admixed with Ar gas with $20 \mathrm{sccm}$, and the total pressure was kept at $2.7 \mathrm{~Pa}$. Measured values of $N$ were on the order of $10^{10} \mathrm{~cm}^{-3}$, and in all gases density increased monotonically with $\mathrm{rf}$ power. The measured $\mathrm{C}$ atom density in fluorocarbon plasmas was much smaller than the $\mathrm{F}$ atom density, which had been measured previously as being on the order of $10^{12} \mathrm{~cm}^{-3} \cdot{ }^{12,13}$ The $\mathrm{C}$ atom density in $\mathrm{CO}$ plasma is larger than the values measured in fluorocarbon plasmas, while a saturating tendency is seen as $\mathrm{rf}$ power increases. On the other hand, the values of $N$ in $\mathrm{CH}_{4}$ plasma are much smaller than those in fluorocarbon plasmas, and it drops below the detection limit at an rf power under $400 \mathrm{~W}$.

Figure 6 shows the $\mathrm{C}$ atom density measured in various source gases as a function of total pressure. The supplied rf power was kept at $300 \mathrm{~W}$, and the flow rates of source gas and $\mathrm{Ar}$ were 10 and $20 \mathrm{sccm}$, respectively. The values of $N$ in $\mathrm{CO}$ plasma increased with pressure almost to 1 $\times 10^{11} \mathrm{~cm}^{-3}$, although a saturating tendency could be seen as in the case of power dependence. On the other hand, in fluorocarbon plasmas, the density decreased gradually with pressure from $(3-5) \times 10^{10}$ to $(1-3) \times 10^{10} \mathrm{~cm}^{-3}$.

\section{DISCUSSION}

We first discuss the reason why the absorption signals of the $94.5 \mathrm{~nm}$ transition group were not detected in spite of the very large transition probability values previously reported. ${ }^{18}$

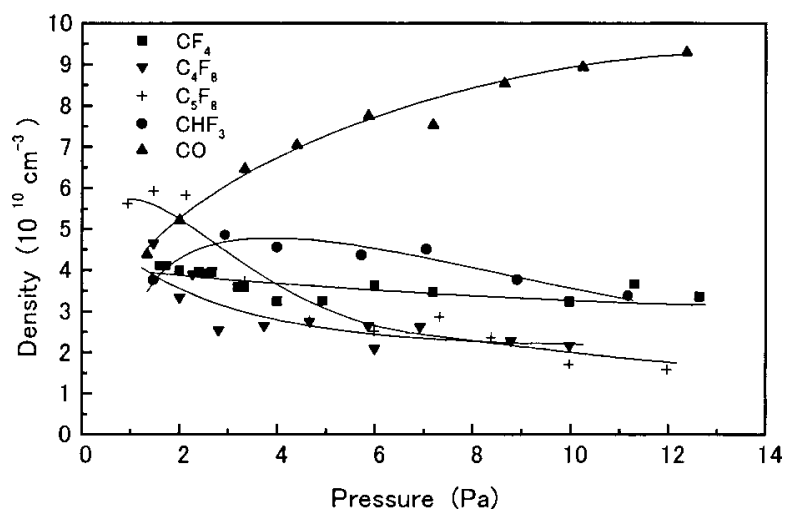

FIG. 6. Pressure dependence of $\mathrm{C}$ atom densities measured in plasmas of fluorocarbon, methane, and CO gases at $\mathrm{rf}$ power of $300 \mathrm{~W}$ with flow rates of source gas and Ar of 10 and $20 \mathrm{sccm}$, respectively.

Assuming the $\mathrm{C}$ atom density measured from the $165 \mathrm{~nm}$ transition group, the expected absorption at $94.5 \mathrm{~nm}$ lines should be $50 \%$. If this were the case, the absorption signal could be found without any difficulty unless the tuning range of our experiment was completely misaligned, which is of little possibility. In order to check the validity of the transition probabilities, we tried to detect those lines with optical emission. However, we could not succeed in this detection. Consequently, we suspect that the reported values of the transition probability might be overestimated by more than an order of magnitude. There remains, however, a slight possibility that the intensity of those emission lines could be very small if the population on the corresponding upper level $\left(2 s 2 p^{3}{ }^{3} S_{1}{ }^{o}\right)$ was very small in our plasma.

Next, we discuss the large differences between the present values of $\mathrm{C}$ atom density and those reported previously by Ito et al. ${ }^{19,20}$ They measured it by using an ultraviolet absorption spectroscopy (UVLAS) technique with a carbon hollow cathode lamp as the light source. The transition used was $2 s^{2} 2 p^{2}{ }^{3} P_{2}-2 s 2 p^{35} S_{2}$ at $296.7 \mathrm{~nm}$, which is a forbidden line, and the obtained values were on the order of $10^{14} \mathrm{~cm}^{-3}$. They also determined the transition probability to be $3.9 \times 10^{4} \mathrm{~s}^{-1}$ from the decay rate of the emission line. ${ }^{20}$ However, another theoretical value of $5.3 \times 10^{8} \mathrm{~s}^{-1}$ was reported for the transition probability of the line, ${ }^{21}$ which is about $10^{4}$ times larger than their estimated value. If the $\mathrm{C}$ atom density were derived from this transition probability, it would be on the order of $10^{10} \mathrm{~cm}^{-3}$, which is consistent with the present measurement.

The major mechanism for the production of $\mathrm{C}$ atoms in a plasma is the electron collisional dissociation of parent gases or radicals; another possible process results from the sputtering of polymer films deposited on the chamber wall. Suzuki et al. suggested that $\mathrm{C}$ and $\mathrm{C}_{2}$ radicals are produced mostly by ion-enhanced chemical reactions with fluorocarbon films on the chamber wall. ${ }^{22}$ In order to estimate the contribution of the sputtering effect in our experiment, the $\mathrm{C}$ atom density in pure Ar plasma was measured after seasoning by $\mathrm{CF}_{4} / \mathrm{Ar}$ plasma. As shown in Fig. 7, the $\mathrm{C}$ atom density in Ar plasma was about half of that in $\mathrm{CF}_{4} / \mathrm{Ar}$ plasma. This result indi- 


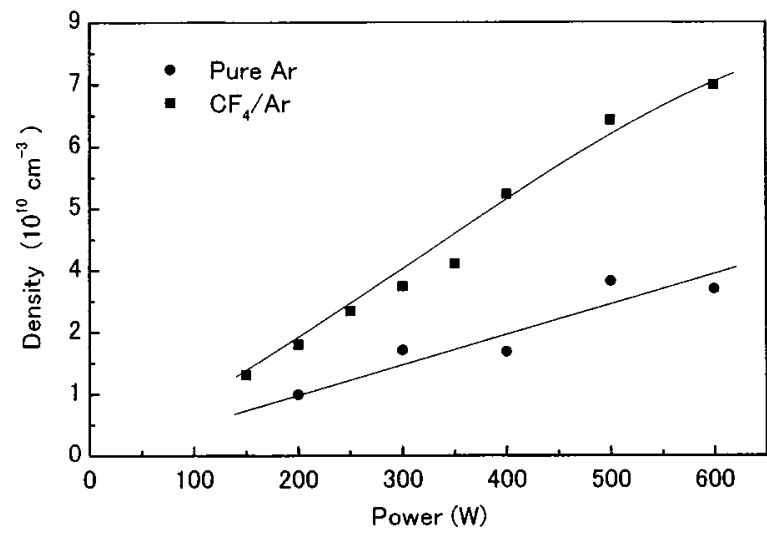

FIG. 7. $\mathrm{C}$ atom densities measured in $\mathrm{CF}_{4} / \mathrm{Ar}$ plasma and in pure Ar plasma after seasoning with $\mathrm{CF}_{4} / \mathrm{Ar}$ plasma as a function of rf power.

cates that $\mathrm{C}$ atoms were generated not only by dissociation reactions in the gas phase but also by sputtering the polymer films on the wall surface. However, the former contribution was shown to be larger in most of the tested gases under our experimental conditions.

Here, we consider the reason why the present values of $\mathrm{C}$ atom density are much smaller than the reported values of other atomic species such as $\mathrm{H}, \mathrm{F}$, and $\mathrm{O}$ under similar conditions. For example, in $\mathrm{CO}$ plasma the following electronic processes are possible for the production of $\mathrm{C}$ atoms in the gas phase by the electron collisional dissociation:

$$
\begin{aligned}
& \mathrm{CO}+e^{-} \rightarrow \mathrm{C}+\mathrm{O}+e^{-}, \\
& \mathrm{CO}+e^{-} \rightarrow \mathrm{C}+\mathrm{O}^{-} .
\end{aligned}
$$

The estimated rate constant for the dissociative attachment process [reaction (3)] is $k=10^{-14}-10^{-13} \mathrm{~cm}^{3} \mathrm{~s}^{-1}$, which is much smaller than the rate constant for the direct dissociation process [reaction (2)] of $k=(0.03-3)$ $\times 10^{-11} \mathrm{~cm}^{3} \mathrm{~s}^{-1} \cdot{ }^{23,24}$ Thus it can be said that in CO plasma $\mathrm{C}$ atoms are produced predominantly by the direct process. In general, the $\mathrm{C}$ atom density $N$ at a steady state is determined by the balance between the production and loss rates as

$$
d N / d t=k_{p} n_{e} N_{\mathrm{CO}}-R_{l} N=0,
$$

where $n_{e}$ is the electron density, $N_{\mathrm{CO}}$ is the density of parent $\mathrm{CO}$ molecules, $k_{p}$ is the production rate constant, and $R_{l}$ is the total loss rate. If we take the above value of $k$ for reaction (2) as $k_{p}$ and assume typical values of $n_{e}$ as $10^{10}$ $-10^{11} \mathrm{~cm}^{-3}$ and $N_{\mathrm{CO}}$ as $3 \times 10^{14} \mathrm{~cm}^{-3}, R_{l}$ should be about $10^{3}-10^{5} \mathrm{~s}^{-1}$ to be consistent with the measured $N$ values of $10^{10}-10^{11} \mathrm{~cm}^{-3}$. The loss mechanisms are reactions in the gas phase and on the wall surface. Possible reactions of $\mathrm{C}$ atoms in the gas phase are the recombination processes:

$$
\begin{aligned}
& \mathrm{C}+\mathrm{O} \rightarrow \mathrm{CO}, \\
& \mathrm{C}+\mathrm{C} \rightarrow \mathrm{C}_{2}, \\
& \mathrm{C}+\mathrm{CO} \rightarrow \mathrm{C}_{2} \mathrm{O} .
\end{aligned}
$$

All of these are three-body reactions whose rate constants are reported as $3 \times 10^{-33}, 2 \times 10^{-34}$, and $6.3 \times 10^{-32} \mathrm{~cm}^{6} \mathrm{~s}^{-1}$, respectively. ${ }^{9,25}$ Under our low-pressure condition, the rates of these reactions become less than $10^{-1} \mathrm{~s}^{-1}$, even if the total gas density is taken as the third-body density, and thus such reactions cannot explain the main loss process. There is also a two-body rate constant for reaction (6) as 2.2 $\times 10^{-11} \mathrm{~cm}^{3} \mathrm{~s}^{-1} \cdot{ }^{26}$ Even with this value, the rate of this reaction is only $2.2 \times\left(10^{-1}-10^{0}\right) \mathrm{s}^{-1}$.

Accordingly, we have to attribute the major loss mechanisms to the surface reactions. In order to substitute the surface loss rate with the equivalent volume loss rate $R_{l}$, let us assume that the total flux of $\mathrm{C}$ atoms is equal to the loss rate in the entire volume as $\Gamma S=R_{l} V N$, where $\Gamma$ is the flux per unit surface, $S$ is the total surface area, and $V$ is the volume. If we assume that $\Gamma$ is determined by the free flux as $\Gamma$ $=(\bar{v} / 4) N$, where $\bar{v}$ is the thermal velocity of $\mathrm{C}$ atoms at 300 $\mathrm{K}, R_{l}$ is estimated to be on the order of $10^{4} \mathrm{~s}^{-1}$. Otherwise, if we take the diffusion flux given by $\Gamma=\left(D_{0} / p \Lambda^{2}\right)$ $\times(V / S) N$, where $D_{0}$ is the diffusion coefficient at 1 Torr, $\Lambda$ is the characteristic diffusion length given by $1 / \Lambda^{2}$ $=(\pi / L)^{2}+(2.4 / R)^{2}$ with the height $L$ and radius $R$ of the chamber, and $p$ is the total pressure, the result for $R_{l}$ stays on the same order with a typical value for $D_{0}$ of 3 $\times 10^{4} \mathrm{~cm}^{2} \mathrm{~Pa} .{ }^{10}$ This is consistent with the required loss rate derived above. In this evaluation, it is assumed that the flux of $\mathrm{C}$ atoms is completely lost at the wall. In the cases of other atomic species, the wall loss probabilities are expected to be very small. As the mechanism of wall loss, the association process [reaction (6)] or further agglomeration reactions such as

$$
C+C_{x} \rightarrow C_{x+1}(x \geqq 2)
$$

could be plausible processes that utilize the wall surface as a third body.

In fluorocarbon plasmas, the obtained $\mathrm{C}$ atom density increases almost linearly with input power except for the case of $\mathrm{CHF}_{3}$ plasma. In these kinds of plasmas, the electron collisional dissociation of parent gases are expected to be followed by the successive dissociation of radicals, e.g., from $\mathrm{CF}_{2}$ and $\mathrm{CF}$ radicals to $\mathrm{C}$ atoms;

$$
\begin{aligned}
& \mathrm{CF}_{2}+e^{-} \rightarrow \mathrm{CF}+\mathrm{F}+e^{-} \text {or } \mathrm{C}+2 \mathrm{~F}+e^{-}, \\
& \mathrm{CF}+e^{-} \rightarrow \mathrm{C}+\mathrm{F}+e^{-} .
\end{aligned}
$$

Miyata et al. reported that the density of $\mathrm{CF}_{2}$ radicals measured in an ECR plasma using infrared laser absorption spectroscopy (IRLAS) is on the order of $10^{12}-10^{13} \mathrm{~cm}^{-3}$, while the density of CF radicals is on the order of $10^{10}$ $-10^{11} \mathrm{~cm}^{-3}{ }^{6}$ These results are consistent with our data obtained in a parallel plate reactor. ${ }^{27}$ If we suppose that the second channel of reaction (9) is the major source for the production of $\mathrm{C}$ atoms and that the rate constant is the same as that of the first channel: $k=3.3 \times 10^{-10} \mathrm{~cm}^{3} \mathrm{~s}^{-1},{ }^{28}$ the estimated production rate would be able to reach the same order as in the case of CO plasma. However, the probability of the second channel might not be so large due to the larger threshold energy. If the production were mainly from $\mathrm{CF}$ radicals through reaction (10), the production rate would be much lower. The observed density of $\mathrm{C}$ atoms in fluorocarbon plasmas is actually smaller than that in CO plasma, but it does not differ by more than one order of magnitude. This 
suggests that the loss rate $R_{l}$ in fluorocarbon plasmas may be smaller when the wall surface is covered with a polymer film instead of a carbon-aggregated material without a fluorine component.

In $\mathrm{CHF}_{3}$ plasma, a saturating tendency was observed in the higher power region. The recombination reactions with $\mathrm{H}$ and $\mathrm{H}_{2}$, that is,

$$
\begin{aligned}
& \mathrm{C}+\mathrm{H} \rightarrow \mathrm{CH}, \\
& \mathrm{C}+\mathrm{H}_{2} \rightarrow \mathrm{CH}+\mathrm{H},
\end{aligned}
$$

might be conceivable loss processes since $\mathrm{H}$ and $\mathrm{H}_{2}$ are produced more abundantly as rf power increases. However, the former is a three-body reaction and the latter is an endothermic reaction with an enthalpy change of $\Delta H=97.1 \mathrm{~kJ} / \mathrm{mol} ;{ }^{3}$ consequently, these reactions can only have a minor influence on the loss process of $\mathrm{C}$ atoms. Binary reactions with $\mathrm{CH}_{2}$ and $\mathrm{CH}_{3}$ might be alternative processes, as in the case of $\mathrm{CH}_{4}$ plasma mentioned below.

It is surprising that the values in $\mathrm{CH}_{4}$ plasma are smaller than those in fluorocarbon plasmas, although the $\mathrm{C}-\mathrm{H}$ bond energy of $3.5 \mathrm{eV}$ is smaller than the $\mathrm{C}-\mathrm{F}$ bond energy of 5.6 $\mathrm{eV}$. It is likely in $\mathrm{CH}_{4}$ plasma that $\mathrm{C}$ atoms are generated in stepwise processes via $\mathrm{CH}_{3}, \mathrm{CH}_{2}$, and $\mathrm{CH}$. If we suppose that $\mathrm{CH}$ radicals are the main source, the density would determine the production rate of $\mathrm{C}$ atoms, whose values may be around $10^{10}$ to $10^{11} \mathrm{~cm}^{-3}$, as estimated from the values obtained previously in a parallel plate reactor. ${ }^{29}$ The relatively small density of $\mathrm{CH}$ is possibly due to the large loss rate by the reaction

$$
\mathrm{CH}+\mathrm{CH}_{4} \rightarrow \mathrm{C}_{2} \mathrm{H}_{5},
$$

which has a reported rate constant of $k=1.0$ $\times 10^{-10} \mathrm{~cm}^{3} \mathrm{~s}^{-1}$. 9

Regardless of the reason for small $\mathrm{CH}$ density, the production rate of $\mathrm{C}$ atoms becomes smaller than that in the $\mathrm{CO}$ plasma by one to two orders of magnitude, even when the rate constant is assumed to be ten times larger than $k$ assigned for reaction (2) and $n_{e}$ is the same. In addition, the loss rate may be large due to the following reactions:

$$
\begin{aligned}
& \mathrm{C}+\mathrm{CH}_{2} \rightarrow \mathrm{C}_{2} \mathrm{H}+\mathrm{H}, \\
& \mathrm{C}+\mathrm{CH}_{3} \rightarrow \mathrm{C}_{2} \mathrm{H}+\mathrm{H}_{2} \text { or } \mathrm{C}_{2} \mathrm{H}_{2}+\mathrm{H},
\end{aligned}
$$

with a relatively large rate constant of $8.3 \times 10^{-11} \mathrm{~cm}^{-3} \mathrm{~s}^{-1}$ in both cases. ${ }^{30}$

Finally, we discuss the difference in the behavior of $\mathrm{C}$ atoms measured in a $\mathrm{CO}$ plasma as a function of gas pressure from those in fluorocarbon plasmas shown in Fig. 6. The reason may be attributed to the increase in the loss rate of $\mathrm{C}$ atoms with pressure through the three-body reaction with source fluorocarbon molecules. A saturating tendency in the $\mathrm{CO}$ plasma may be due to the association reaction between $\mathrm{C}$ atoms in the gas phase as pressure increases. A similar behavior was observed previously in the case of $\mathrm{F}$ atoms, where the density of $\mathrm{F}$ atoms increased monotonically up to 5.3 Pa but started to decrease in the higher pressure region. ${ }^{13}$ In addition to those reactions, the change in plasma parameters does influence the production rate of $\mathrm{C}$ atoms as pres- sure changes. For a more quantitative argument, however, we need to have data on the behavior of plasma parameters such as electron density and temperature.

\section{CONCLUSIONS}

A tunable VUV laser in the 94.5 and $165.7 \mathrm{~nm}$ ranges was generated by the two-photon resonance/four wave mixing technique in Xe gas, and the absolute atomic carbon density in an ICP source was successfully measured by using absorption spectroscopy. C atom density increased with an increase in rf power in all of the tested source gases at applied power of 150-600 W. When the pressure was varied, the density behaviors were different between fluorocarbon and $\mathrm{CO}$ source gases. The absolute values of $\mathrm{C}$ atom density were on the order of $10^{10} \mathrm{~cm}^{-3}$, which are much smaller than the measured values of other atomic species such as $\mathrm{F}$ and $\mathrm{O}$ under similar conditions. ${ }^{14}$ The major reason for this result is attributed to the larger wall loss rate of $\mathrm{C}$ atoms, especially when the wall is covered with carbon-aggregated material.

Although the measured density of $\mathrm{C}$ atoms is relatively small, this does not necessarily mean that the contributions of $\mathrm{C}$ atoms to various processes are negligible. The small density is mainly due to the large loss rate, especially in $\mathrm{CO}$ plasma, and the production rate may not be small. Therefore in order to argue the beneficial or deleterious contributions of $\mathrm{C}$ atoms in specific material processes, such as the selective etching of $\mathrm{SiO}_{2}$ on $\mathrm{Si}$ and under photoresist or the deposition of diamond and diamond-like carbon films, it is necessary to systematically measure $\mathrm{C}$ atoms and carbon aggregomers $\mathrm{C}_{x}(x \geqq 2)$ together with other radicals such as $\mathrm{CF}_{x}, \mathrm{CH}_{x}(x$ $=1-3$ ), and larger polymerized species while giving attention to the etching and deposition characteristics. For this purpose, the present study has shown that the VUVLAS method is a useful tool for the absolute measurement of $\mathrm{C}$ atoms.

\section{ACKNOWLEDGMENT}

This work was supported in part by a Grants-in-Aid for Scientific Research from the Ministry of Education, Culture, Sports Science and Technology of Japan.

${ }^{1}$ S. Den, T. Kuno, M. Ito, and M. Hori, J. Vac. Sci. Technol. A 15, 2880 (1997).

${ }^{2}$ M. E. Coltrin and D. S. Dandy, J. Appl. Phys. 74, 5803 (1993).

${ }^{3}$ B. W. Yu and S. L. Girshick, J. Appl. Phys. 75, 3914 (1994).

${ }^{4}$ K. Teii, H. Ito, M. Hori, T. Takeo, and T. Goto, J. Appl. Phys. 87, 4572 (2000).

${ }^{5}$ M. Lieberman and A. J. Lichtenberg, Principles of Plasma Discharge and Materials Processing (Wiley, New York, 1994).

${ }^{6}$ K. Miyata, M. Hori, and T. Goto, J. Vac. Sci. Technol. A 14, 2343 (1996).

${ }^{7}$ P. Das, G. S. Ondrey, N. van Veen, and R. Bersohn, J. Chem. Phys. 79, 724 (1983).

${ }^{8}$ G. C. Herring, M. J. Dyer, L. E. Jusinsky, and W. K. Bischel, Opt. Lett. 13, 360 (1988).

${ }^{9}$ D. Husain and L. J. Kirsch, Trans. Faraday Soc. 67, 2025 (1971).

${ }^{10}$ H. Ito, K. Teii, H. Funakoshi, M. Ito, and T. Goto, J. Appl. Phys. 88, 4537 (2000).

${ }^{11}$ A. Goehlich, T. Kawetzki, and H. F. Doebele, J. Chem. Phys. 108, 9362 (1998).

${ }^{12}$ K. Tachibana and H. Kamisugi, Appl. Phys. Lett. 74, 2390 (1999). 
${ }^{13}$ K. Tachibana, H. Kamisugi, and T. Kawasaki, Jpn. J. Appl. Phys., Part 1 38, 4367 (1999).

${ }^{14}$ K. Tachibana, Plasma Sources Sci. Technol. 11, A166 (2002).

${ }^{15}$ R. Hilbig and R. Wallenstein, IEEE J. Quantum Electron. QE-19, 194 (1983).

${ }^{16}$ H. F. Döebele, U. Czarnetzki, and A. Goehlich, Plasma Sources Sci. Technol. 9, 477 (2000).

${ }^{17}$ R. W. Falcone and J. Bokor, Opt. Lett. 8, 21 (1983).

${ }^{18}$ W. L. Wiese and G. A. Martin, Wavelengths and Transition Probabilities for Atoms and Atomic Ions, NSRDS-NBS 68 (U.S. Government Printing Office, Washington, DC, 1980); see also http:physics.nist.gov/asd. The transition probabilities in the latter reference, which have been used in the present data analyses, are smaller than those in the former reference by $15 \%-20 \%$ for the relevant transitions.

${ }^{19}$ H. Ito, M. Ikeda, M. Ito, M. Hori, and T. Goto, Jpn. J. Appl. Phys., Part 2 36, L880 (1997).

${ }^{20}$ H. Ito, M. Ito, M. Hori, A. Kono, and T. Goto, Jpn. J. Appl. Phys., Part 2 36, L1616 (1997).
${ }^{21}$ R. Rayling and P. Larkins, Optical Emission Lines of the Elements (Wiley, Chichester, 2000)

${ }^{22}$ C. Suzuki, K. Sasaki, and K. Kadota, Jpn. J. Appl. Phys., Part 1 38, 6896 (1999).

${ }^{23}$ A. I. Maksimov, L. S. Polak, A. F. Sergienko, and D. I. Slovetskii, High Energy Chem. 13, 311 (1979).

${ }^{24}$ T. G. Beuthe and J. S. Chang, Jpn. J. Appl. Phys., Part 1 36, 4997 (1997).

${ }^{25}$ A. R. Fairbaim, Proc. R. Soc. London, Ser. A 312, 207 (1969).

${ }^{26}$ F. F. Martinotti, M. J. Welch, and A. P. Wolf, Chem. Commun. (London) 1968, 115 (1968) through NIST Chemical Kinetics Database No. 17 (1998).

${ }^{27}$ K. Takahashi, A. Itoh, T. Nakamura, and K. Tachibana, Thin Solid Films 374, 303 (2000).

${ }^{28}$ T. Kimura and K. Ohe, Plasma Sources Sci. Technol. 8, 553 (1999).

${ }^{29}$ K. Tachibana, T. Mukai, A. Yuuki, Y. Matsui, and H. Harima, Jpn. J. Appl. Phys., Part 1 29, 2156 (1990).

${ }^{30}$ J. M. Larson, M. T. Swihart, and S. L. Girshick, Diamond Relat. Mater. 8, 1863 (1999). 